\title{
Low dose warfarin treatment for calcinosis in patients with systemic sclerosis
}

\author{
T Cukierman, E Elinav, M Korem, T Chajek-Shaul
}

Ann Rheum Dis 2004;63:1341-1343. doi: 10.1136/ard.2003.014431

\begin{abstract}
Objective: To evaluate the effect of low doses of warfarin in patients with systemic sclerosis with disseminated subcutaneous calcinosis.

Methods: Three patients with disseminated subcutaneous calcinosis were treated with low doses of warfarin for 1 year. Subcutaneous calcinotic lesions, coagulation blood parameters, and the tendency for bleeding were followed up during the year.

Results: Two of the patients, who had newly diagnosed, diffuse, and relatively small calcinotic lesions, responded to warfarin treatment, with complete resolution of the calcinosis. The other patient, with larger and longer standing calcinotic lesions, did not respond to warfarin treatment. None of the three patients showed a prolongation of prothrombin time or partial thromboplastin time, nor did any have an increased tendency for bleeding.

Conclusions: Low dose warfarin may serve as an effective treatment for calcinosis in a selected group of patients who have small and relatively new onset calcinosis. This treatment does not prolong the coagulation of blood and there is no increased tendency for bleeding.
\end{abstract}

$\mathrm{D}$ iffuse calcinosis is a common manifestation of systemic sclerosis, mainly affecting the extremities. ${ }^{1}$ The subcutaneous calcium deposits may erode the skin and predispose these areas to secondary infection, yet no currently approved medical treatment exists. Rare anecdotal reports suggest that low dose warfarin may have a role in reducing the size of calcinotic plaques. ${ }^{2-4}$ We describe three patients who had multiple calcinotic lesions secondary to systemic sclerosis and who were treated with warfarin for 1 year, with results varying in accordance with the age and size of the calcinotic lesions.

\section{CASE REPORTS}

\section{Case 1}

A 35 year old female patient of Arab origin had limited cutaneous systemic sclerosis, manifested as severe Raynaud's phenomenon, oesophageal dysmotility, hidebound skin overlying both hands and face resulting in microstomia and puffy hands and pulmonary hypertension, positive antinuclear antibodies (three out of four), and negative anticentromere antibodies. Penicillamine treatment was ineffective, and the patient was treated with oral calcium channel blockers and with infusions of prostacyclin analogue.

During follow up the patient was found to develop multiple painless subcutaneous calcium deposits on her knuckles and elbows, up to $2 \mathrm{~cm}$ in diameter. She consented to treatment with warfarin, which was started at a low dose of $1 \mathrm{mg} /$ day. Within 2 months all the calcinotic lesions had completely disappeared, leaving only small areas of skin discolouration.
Treatment was continued with warfarin for a year without recurrence of the calcinotic lesions. On follow up (at 2 years), no recurrence of the calcinotic lesions was seen. During treatment the prothrombin time (PT) and partial thromboplastin time (PTT) were repeatedly measured and were found to remain within normal values, with no clinically increased tendency for bleeding noted.

\section{Case 2}

A 30 year old female patient of Arab origin was known to have had diffuse cutaneous systemic sclerosis for 10 years, including Raynaud's phenomenon, progressive sclerodactyly, telangiectasias, arthritis, diffusely thickened skin over her extremities, and positive antitopoisomerase antibodies. The patient was treated with an intravenous prostacyclin analogue for her resistant Raynaud's phenomenon, with partial response. Her past medical history was significant for two episodes of self resolving pleural and pericardial effusion.

During follow up the patient developed bilateral painless subcutaneous calcium deposits on her knuckles and elbows, up to $2 \mathrm{~cm}$ in diameter. One of the lesions was painful and found to be secondarily infected. The infection resolved with systemic antibiotics, and treatment with low dose warfarin ( $1 \mathrm{mg}$ daily) was then started (after the patient consented).

Within 2 months of starting warfarin a marked improvement was noted, with complete disappearance of all the calcinotic lesions. Only small areas of skin discolouration remained in place of the calcinotic lesions. The patient continued to take warfarin for a year, with no evidence of recurrent calcinotic lesions. On follow up for an additional year, no recurrence of the calcinotic lesions was seen. During that time the PT and PTT remained normal, with the patient having no tendency for excess bleeding.

\section{Case 3}

A 70 year old female patient of Jewish origin was known to have had limited cutaneous systemic sclerosis for 20 years, on the basis of characteristic skin changes, telangiectasias, oesophageal dysmotility, calcinosis, Raynaud's phenomenon, and arthritis. Previous attempts to treat her limited systemic sclerosis with penicillamine and colchicine had failed to slow the progression of her illness.

On physical examination the patient appeared cachectic, with normal cardiac, pulmonary and abdominal examination, and characteristic sclerodermatous skin changes, including diffuse thickening, taut fingers with flexion contractures, the typical microstomia, and several large calcinotic deposits over the bridge of the nose, elbows, and breasts. Laboratory tests, including blood count, biochemistry, chest radiography, echocardiography, and pulmonary function tests were unremarkable, with no apparent pulmonary or renal involvement of the systemic disorder.

Abbreviations: PT, prothrombin time; PT, partial thromboplastin time 
Table 1 Treatments modalities for subcutaneous calcinosis

\begin{tabular}{|c|c|c|c|c|}
\hline Treatment modality & No & Diagnosis & Outcome & Reference \\
\hline \multicolumn{5}{|l|}{ Disodium etidronate } \\
\hline $10 \mathrm{mg} / \mathrm{kg}$ & 3 & Dermatomyositis & 5/6 Progression* & Metzger et al (1974) $)^{5}$ \\
\hline$>20 \mathrm{mg} / \mathrm{kg}$ & 3 & Scleroderma & & \\
\hline Alendronate $10 \mathrm{mg} / \mathrm{kg}$ & 1 & Juvenile dermatomyositis & Clinical and radiological response & Mukamel et al(2001) ${ }^{6}$ \\
\hline Alendronate & 1 & Juvenile dermatomyositis & Clinical and radiological response & Oliveira and Wolff (2003) \\
\hline \multicolumn{5}{|l|}{ Aluminium hydroxide } \\
\hline $120 \mathrm{ml} /$ day & 1 & & No change-short follow up & Hudson et al $(1974)^{8}$ \\
\hline Surgical removal & 7 & Scleroderma & 6/7 Beneficial $\dagger$ & Mendelson et al $(1977)^{9}$ \\
\hline \multirow[t]{2}{*}{ Carbon dioxide laser } & 6 & Systemic sclerosis & 3 Good responsef & Bottomley et al $(1996)^{10}$ \\
\hline & & & $\begin{array}{l}2 \text { Moderate response } \\
1 \text { Poor response }\end{array}$ & \\
\hline $\begin{array}{l}\text { Intralesional adrenal steroids } \\
\text { injection }\end{array}$ & 1 & Scleroderma & Smaller and less painful ulcer after 3 months & Hazen et al (1982) ${ }^{11}$ \\
\hline \multicolumn{5}{|l|}{ Diltiazem } \\
\hline $120 \mathrm{mg} /$ day & 1 & Scleroderma & Dramatic improvement at follow up of 2 years & Dolan ef al $(1995)^{12}$ \\
\hline $180 \mathrm{mg} /$ day & 12 & Scleroderma & $\begin{array}{l}6 \text { Unchanged§ } \\
3 \text { Slight regression } \\
3 \text { Intensification }\end{array}$ & Vayssairat et al $(1998)^{13}$ \\
\hline Minocycline & 9 & Scleroderma & $\begin{array}{l}8 \text { Improvement in the incidence of ulceration } \\
\text { and inflammation } \\
1 \text { Radiographic improvement }\end{array}$ & Robertson et al $(2003)^{14}$ \\
\hline \multicolumn{5}{|c|}{ 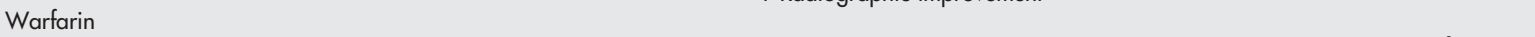 } \\
\hline \multirow[t]{2}{*}{$1 \mathrm{mg} /$ day phase $\mathrm{I}$} & 4 & Dermatomyositis & 1 Improvement in bone scan & Berger et al $(1987)^{2}$ \\
\hline & & Scleroderma & $\begin{array}{l}1 \text { Improvement in bone scan and plain film } \\
2 \text { No change }\end{array}$ & \\
\hline $1 \mathrm{mg} /$ day phase II & 8 & Placebo treatment & $\begin{array}{l}2 / 3 \text { Treatment group had improvement in } \\
\text { bone scan scores }\end{array}$ & \\
\hline & & & 0/4 Placebo group showed improvement & \\
\hline \multirow[t]{2}{*}{ Warfarin $1 \mathrm{mg} /$ day } & 6 & Dermatomyositis & 5 Worsening & Lassoued et al $(1988)^{3}$ \\
\hline & & Scleroderma & 1 Stable & \\
\hline Warfarin $1 \mathrm{mg} /$ day & 1 & Scleroderma & Clinical and radiographic improvement & Yoshida and Torikai(1993) $^{4}$ \\
\hline Anti-TNF & 2 & $\begin{array}{l}\text { Idiopathic inflammatory } \\
\text { myositis }\end{array}$ & $\begin{array}{l}\text { Regression and non-tender in follow up of } \\
6-14 \text { months }\end{array}$ & Maillard $(2002)^{15}$ \\
\hline Anti-TNF & 2 & Juvenile dermatomyositis & $\begin{array}{l}\text { No progression and non-tender in follow up } \\
\text { of } 2-10 \text { months }\end{array}$ & Maillard et al $(2001)^{16}$ \\
\hline
\end{tabular}

During her follow up, especially disturbing to her were the painless white deposits distributed over her face and extremities, gradually enlarging over the years before her admission (reaching up to $5 \mathrm{~cm}$ in diameter).

The patient consented to a therapeutic trial with low dose warfarin ( $1 \mathrm{mg}$ ) in an attempt to alleviate the severely disfiguring calcinotic lesions. Throughout the year of follow up no reduction in the size of her calcinotic lesions was seen, but there was no tendency for excess bleeding or a prolongation of the PT and PTT.

\section{DISCUSSION}

Subcutaneous calcium deposition is a disturbing complication affecting patients who have connective tissue diseasesin particular, systemic sclerosis and dermatomyositis. Calcinosis may result in the formation of painful ulcers that can be easily infected. The mechanism of calcinosis formation is not entirely understood, and no effective treatment is available. ${ }^{1}$ Throughout the years many treatment regimens have been tried and anecdotal case reports and small series have shown some or little improvement with diltiazem, adrenal steroids, carbon dioxide laser treatment, surgical treatment, and aluminium hydroxide. Better results have been obtained with aledronate, anti-tumour necrosis factor (anti-TNF), and warfarin (table 1$).^{2-16}$

In 1987 Berger et al offered a possible mechanism for the development of calcinosis. ${ }^{2}$ Levels of the calcium binding amino acid $\gamma$-carboxyglutamic acid were found to be high in areas of calcinosis, so it was postulated that it might have a role in binding large amounts of calcium salts at the affected areas, leading to the formation of calcinosis. ${ }^{17}$
The carboxylation of glutamine, leading to the formation of the $\gamma$-carboxyglutamic acid, is coupled to the vitamin $\mathrm{K}$ cycle and is inhibited by warfarin. ${ }^{18}$ Thus it was suggested that carboxylation of glutamine to $\gamma$-carboxyglutamic acid, leading to calcinosis, might be inhibited by low doses of warfarin. At low doses, warfarin does not prolong the PT or PTT, does not cause an excess bleeding tendency, and thus requires no laboratory follow up of the patients' coagulation status.

Two small clinical trials tested this hypothesis. The results of the first trial ${ }^{2}$ demonstrated a radiological improvement in all four patients treated with warfarin, but a clinical reduction in calcinotic lesion size in only one of the four patients. The responsive patient had small calcinotic lesions with a low bone scan score, thought to represent a mild calcinotic process, whereas the other three patients had larger calcinotic plaques and high bone scan scores, thought to represent a more advanced and longer standing calcinotic process.

Lassoued et al reported their experience of using warfarin to treat six patients with diffuse calcinosis for 1 year. ${ }^{3}$ No significant clinical reduction in calcinotic lesion size occurred in any of the patients. All six patients had extensive calcinosis (Berger grade $4+$ ) which had been present for a long time before the start of treatment.

Yoshida and Torikai described a patient with longstanding, yet mild, calcinosis (Berger grade 2) who was treated with low dose warfarin ( $1 \mathrm{mg}$ ). Complete clinical and radiographic response was noted. ${ }^{4}$

Our three patients had multiple calcinotic lesions and were treated with $1 \mathrm{mg}$ of warfarin for a period of 1 year. The first two patients showed a rapid clinical response, with complete disappearance of all calcinotic lesions after 2 months of 
treatment. In the third patient, no change was noted in the size of the calcinotic lesions after a year of treatment. The two major differences between the responding and non-responding patients were the duration of the calcinotic lesions before the start of treatment, and their size. In the two responders the lesions developed relatively shortly before the start of treatment and were all smaller than $2 \mathrm{~cm}$ in diameter. In the non-responder the lesions were known to have been present for at least 5 years and were of larger diameter.

On the basis of our observations and the previously described cases, $^{2-4}$ we conclude that two main factors influence the response to warfarin treatment in calcinosis: the size of the calcinotic lesions, and the time lapse between the formation of the calcinotic lesions and the start of treatment.

One possible explanation for the importance of these factors may be that relatively newer onset and smaller calcinotic lesions are more dependent for their growth on the amount and availability of $\gamma$-carboxyglutamic acid at the nidus site, and thus are more prone to inhibition by warfarin. The longer standing and larger lesions, on the other hand, are composed of greater amounts of surrounding ectopic calcium deposits, serving by themselves as a nidus for further calcification. As a result these lesions are less dependent for their growth on the availability of $\gamma$ carboxyglutamic acid and are more resistant to the inhibitory effects of warfarin.

A drawback of this treatment that still has to be examined is the potentially enhancing effect of warfarin on artery calcification as demonstrated in rat models. ${ }^{19}$ It is not clear yet whether this effect occurs in humans.

In conclusion, there still seems to be no highly effective treatment for calcinosis. We suggest that low dose warfarin may be effective in selected patients with systemic sclerosis who have early and mild calcinosis. At low doses this treatment is well tolerated, with a very low risk of bleeding. Larger, controlled studies are needed to validate this observation.

\section{Authors' affiliations \\ T Cukierman, E Elinav, M Korem, T Chajek-Shaul, Department of Medicine, Hadassah University Hospital, Mount Scopus, Jerusalem,} Israel
Correspondence to: Dr T Chajek-Shaul, Department of Medicine, Hadassah University Hospital, Mount Scopus, PO Box 24035, Jerusalem 91240, Israel; chajek@hadassah.org.il

Accepted 12 November 2003

\section{REFERENCES}

1 Black CM. Scleroderma- clinical aspects. J Intern Med 1993;234:115-18.

2 Berger RG, Featherstone GL, Raasch RH, McCartney WH, Hadler NM. Treatement of calcinosis universalis with low-dose warfarin. Am J Med 1987;83:72-6.

3 Lassoued K, Saiag P, Anglade MC, Roujeau JC, Touraine RL. Failure of warfarin in treatment of calcinosis universalis. Am J Med 1988;84:795-6.

4 Yoshida S, Torikai K. The effects of warfarin on calcinosis in a patient with systemic sclerosis. J Rheumatol 1993;20:1233-5.

5 Metzger AL, Singer FR, Bluestone R, Pearson CM. Failure of disodium etidronate in calcinosis due to dermatmyositis and scleroderma. N Engl J Med 1974;291:1294-6.

6 Mukamel M, Horev G, Mimouni M. New insight into calcinosis of juvenile dermatomyositis: a study of composition and treatment. J Pediatr $2001 ; 138: 763-6$

7 Oliveira SKF, Wolff C. Alendronate: is it efficacious therapy in the treatment of calcinosis in juvenile dermatomyositis? [abstract] Ann Rheum Dis 2003;62(suppl I): abstr 0389.

8 Hudson PM, Jones PE, Robinson TW, Dent CE. Extensive calcinosis with minimal scleroderma: treatment of ectopic calcification with aluminum hydroxide. Proc R Soc Med 1974;67:1 166-8.

9 Mendelson BC, Linscheid RL, Dobyns JH, Muller SA. Surgical treatment of calcinosis cutis in the upper extremity. $J$ Hand Surg [Am] 1977;2:318-24.

10 Bottomley WW, Goodfield MJ, Sheehan-Dare RA. Digital calcification in systemic sclerosis: effective treatment with good tissue preservation using carbon dioxide laser. $\mathrm{Br} J$ Dermatol 1996;135:302-4.

11 Hazen PG, Walker AE, Carney JF, Stewart JJ. Cutaneous calcinosis of scleroderma. Successful treatment with intralesional adrenal steroids. Arch Dermatol 1982;1 18:366-7.

12 Dolan AL, Kassimos D, Gibson T, Kingsley GH. Diltiazem induces remission of calcinosis in scleroderma. Br J Rheumatol 1995;34:576-8.

13 Vayssairat M, Hidouch D, Abdoucheli-Baudat, Gaitz JP. Clinical significane of subcutaneous calcinosis in patients with systemic sclerosis. Does diltiazem induce its regression? Ann Rheum Dis 1998;57:252-4.

14 Robertson LP, Marshall RW, Hickling P. Treatment of cutaneous calcinosis in limited systemic sclerosis with minocycline. Ann Rheum Dis 2003;62:267-9.

15 Maillard SM. The treatment of persistent severe idiopathic inflammatory myositis with anti-TNF therapy [abstract]. Ann Rheum Dis 2002;61(suppl I): abstr 0286 .

16 Maillard SM, Wilkinson N, Rily P, Beresford M, Davidson J, Murray KJ. The treatment of persistent severe idiopathic inflammatory myositis (IIM) with antiTNF $\alpha$ therapy [abstract]. Ann Rheum Dis 2001;60(suppl I): abstr 770.

17 Lian JB, Pachman LM, Gundberg CM, Partridge RE, Maryjowski MC. Gamma-carboxyglutamate excretion and calcinosis in juvenile dermatomyositis. Arthritis Rheum 1982;25:1094-100.

18 Gallop PM, Lian JB, Hauschka PV. Carboxylated calcium binding proteins and vitamin K. N Engl J Med 1980;302:1460-6.

19 Price PA, Faus SA, Williamson MK. Warfarin induced artery calcification is accelerated by growth and vitamin D. Arterioscler Thromb Vasc Biol 2000;20:317-27. 